\title{
Changing European storm loss potentials under modified climate conditions according to ensemble simulations of the ECHAM5/MPI-OM1 GCM
}

\author{
J. G. Pinto ${ }^{1}$, E. L. Fröhlich ${ }^{1,2}$, G. C. Leckebusch ${ }^{3}$, and U. Ulbrich ${ }^{3}$ \\ ${ }^{1}$ Institut für Geophysik und Meteorologie, Universität zu Köln, Germany \\ ${ }^{2}$ Institut für Physik der Atmosphäre, Johannes Gutenberg-Universität Mainz, Germany \\ ${ }^{3}$ Institut für Meteorologie, Freie Universität Berlin, Germany
}

Received: 18 September 2006 - Revised: 18 December 2006 - Accepted: 30 January 2007 - Published: 8 February 2007

\begin{abstract}
A simple storm loss model is applied to an ensemble of ECHAM5/MPI-OM1 GCM simulations in order to estimate changes of insured loss potentials over Europe in the 21 st century. Losses are computed based on the daily maximum wind speed for each grid point. The calibration of the loss model is performed using wind data from the ERA40Reanalysis and German loss data. The obtained annual losses for the present climate conditions (20C, three realisations) reproduce the statistical features of the historical insurance loss data for Germany.
\end{abstract}

The climate change experiments correspond to the SRESScenarios A1B and A2, and for each of them three realisations are considered. On average, insured loss potentials increase for all analysed European regions at the end of the 21st century. Changes are largest for Germany and France, and lowest for Portugal/Spain. Additionally, the spread between the single realisations is large, ranging e.g. for Germany from $-4 \%$ to $+43 \%$ in terms of mean annual loss. Moreover, almost all simulations show an increasing interannual variability of storm damage. This assessment is even more pronounced if no adaptation of building structure to climate change is considered. The increased loss potentials are linked with enhanced values for the high percentiles of surface wind maxima over Western and Central Europe, which in turn are associated with an enhanced number and increased intensity of extreme cyclones over the British Isles and the North Sea.

Correspondence to: J. G. Pinto

(jpinto@meteo.uni-koeln.de)

\section{Introduction}

Along with floods (e.g. Elbe River 2002, cf. Ulbrich et al., 2003a,b), winter storms associated with the passage of intense extra-tropical cyclones are one of the primary natural hazards over Europe (SwissRe, 2000). During December 1999, three severe storms hit Europe (e.g., Ulbrich et al., 2001), causing insured losses above 10 billion EUR (MunichRe, 2001). The total economic losses were roughly twice as much. The insured loss attributed to only one of those storms (Lothar, 26 December 1999) amounted to 5.9 billion EUR (11.3 billion EUR for economic loss), primarily in France (MunichRe, 2001). In fact, MunichRe (1999, 2001) estimate that storm events were responsible for more than $50 \%(60 \%)$ of total economic (insured) losses over Germany for the period 1970-1999. Furthermore, a significant increase in losses has been detected during the second half of the 20th century (Berz, 2001). Even though this loss increase is mainly ascribed to socio-economic factors (e.g., economic and demographic growth), variations of meteorological conditions can also contribute considerably to modify both the number and strength of natural disasters (e.g., Berz, 2001; Emanuel, 2005; Webster et al., 2005; SwissRe, 2006). Moreover, there are first indications that losses in Europe could increase during the 21st century (SwissRe, 2006; Leckebusch et al., 2007).

Temporal changes of storm activity over Europe can be quantified by analysing the frequency distributions of cyclones and/or local wind speeds. This aspect has been explored in many recent publications based on observational datasets: While some authors (e.g., Schinke, 1993; Lambert, 1996; Geng and Sugi, 2001; Paciorek et al., 2002) identified significant changes in extra-tropical cyclone activity

Published by Copernicus GmbH on behalf of the European Geosciences Union. 
during the latter half of the 20th century in the Northern Hemisphere, other authors (e.g., von Storch et al., 1993; WASA-Group, 1998; Bärring and von Storch, 2004) objected that these trends may be unreliable because of the inhomogeneities in data series, and that the recent increase in activity could be a part of the strong natural inter-decadal variations of the storm climate.

Within this context, it is important to analyse to what extent frequency and intensity of winter storms may change under the enhanced GHG forcing conditions in the current (21st) century (IPCC, 2001). Future changes of storm activity have been found in global climate model (GCM) simulations (e.g., Lambert, 1995; Carnell et al., 1996; Knippertz et al., 2000; Lambert et al., 2002; Geng and Sugi, 2003; Raible and Blender, 2004; Leckebusch and Ulbrich, 2004; Lambert and Fyfe, 2006; Leckebusch et al., 2006; Bengtsson et al., 2006; Pinto et al., 2006) conducted with prescribed enhanced greenhouse gas forcing according to different SRES scenarios (IPCC, 1996, 2001; Nakićenović et al., 2000). Many of these climate change studies point to an increase in the number of intense low pressure systems over the North Atlantic, while the frequency of weak cyclones may be reduced. However, uncertainties with respect to the magnitude of the changes remain, as the results are sensitive to both the choice of data as well as the choice of methods. Typically, the extreme wind gusts are associated with the occurrence of deep and intense cyclones. Knippertz et al. (2000) associated the enhanced number of extreme wind situations in one ECHAM4 GHG simulation with an augmented number of deep cyclones (particularly under $970 \mathrm{hPa}$ ) over Northern Europe adjacent ocean areas. More recently, Leckebusch et al. (2006) have juxtaposed the changes in the 5\% strongest cyclones (measured by the intensity of circulation) and for all systems, and associated these with changes in higher wind percentiles for several GCMs (ECHAM4, ECHAM5, HadCM3, HadAM3P). Results for the 5\% strongest cyclones indicate enhanced cyclone activity for western parts of Central Europe in all GCM simulations, which is consistent with enhanced frequency of wind extremes over large parts of Europe (Leckebusch et al., 2006).

While a wide range of publications focuses on the past and future climatology of storms, little has been publicly available in terms of interdisciplinary approaches, e.g. combining meteorological and insurance aspects of storms (Klawa and Ulbrich, 2003). This fact may be attributed to the lack of loss data (which is required to estimate the extent of damage caused by severe storms) available for researchers. The methodology used here was initially developed by Klawa and Ulbrich (2003) and has recently been used by Leckebusch et al. (2007) to assess changes of loss potentials over Germany and England in a multi-model approach. While that study considered only one simulation per GCM, we focus here on an ensemble of climate change simulations of the ECHAM5/MPI-OM1 GCM in order to estimate the sensitivity of the results against the GCMs internal variability.
Hence, we analyse changes in insured loss potentials over Europe between the current and future climate based on the SRES scenarios A1B and A2 (Nakićenović et al., 2000) considering three simulations per experiment. These simulations have been analysed in terms of changes of synoptic activity and cyclone characteristics in Pinto et al. (2007).

The storm loss model is calibrated with recent ERA40Reanalysis data. As investigations of Palutikof and Skellern (1991) and Klawa and Ulbrich (2003) imply that the 98th percentile of the daily maximum wind speed is a reasonable threshold for initiation of damage, special attention was given to changes in this percentile of local wind speed in Pinto et al. (2007). Their results show an increase of the 98th percentile values over Western Europe for both the A1B and A2 experiments. Here, we further explore the consequences for these enhanced wind speeds to insurance losses over $\mathrm{Eu}-$ rope, considering the following regions: Germany, United Kingdom, France, Norway/Sweden and Portugal/Spain.

Information about data sets is given in Sect. 2, followed by a detailed description of the storm loss model in Sect. 3 . Section 4 analyses extreme winds and storm loss values for Germany for present climate conditions in both for Reanalysis and GCM data. Changes in cyclone activity and extreme winds in a future climate are presented in Sect. 5. The correspondent changes in storm losses are analysed in Sect. 6. A summary and a short discussion conclude this paper.

\section{Data}

\subsection{Climate simulations of ECHAM5/MPI-OM1}

The analysed climate change experiments were performed with the ECHAM5/MPI-OM1 GCM, a coupled atmosphereocean model developed at the Max-Planck-Institute (MPI) for Meteorology in Hamburg (Germany). The atmospheric component is the spectral model ECHAM5 (Roeckner et al., 2003) at T63 horizontal resolution, which corresponds to a spatial resolution of circa $1.875^{\circ} \times 1.875^{\circ}(\sim 200 \mathrm{~km})$. The oceanic component MPI-OM1 includes a dynamic sea ice model (Marsland et al., 2003). Compared to older versions of the coupled ECHAM-model, the ECHAM5/MPI-OM1 is able to provide a stable climate without flux adjustment.

An ensemble of realisations with different forcings is considered. For the recent climate, the simulations (hereafter 20C) were computed with radiative forcing according to historical GHG and aerosol concentrations for the period 18602000. The initial conditions for the three runs are three different states of the 500-yr-long pre-industrial control simulation, which was computed with constant 1860 GHG concentrations. For future climate conditions, two experiments are considered, following the SRES scenarios A1B and A2 (Nakićenović et al., 2000) for the period 2001-2100. The $\mathrm{CO}_{2}$ concentrations increase from $367 \mathrm{ppm}$ (year 2000) to $703 \mathrm{ppm}$ and $836 \mathrm{ppm}$ by the year 2100 for scenarios A1B 
and A2, respectively. The scenario simulations are initialized with the final states of the $20 \mathrm{C}$ simulations, and therefore they may be considered as extensions of the previous runs. Analysis period is the winter half year (ONDJFM), when intense storms typically occur. This is an appropriate simplification due to the fact that $98 \%$ of all storm damage is ascribed to winter storms (MunichRe, 1999). Climate signals refer to the changes between end of the 21st century (20602100) and recent climate conditions (1960-2000).

For the wind data, particular attention is given to the daily maximum near-surface $(10 \mathrm{~m})$ wind speed (hereafter wimax), which is based on the internal time step of the atmospheric model (circa $15 \mathrm{~min}$ ). Additionally, the largest daily value of the four 6-hourly wind speed values (at reported time, based on a $10 \mathrm{~min}$ average, not maximum of the last $6 \mathrm{~h}$, hereafter w6h) is analysed for comparison with ERA40 data.

\subsection{ERA40-reanalysis}

Near-surface $(10 \mathrm{~m})$ wind data of the ERA40-Reanalysis (hereafter ERA40, cf. Uppala et al., 2004) provided by European Centre for Medium Range Weather Forecasts (ECMWF) are used for model calibration and validation. The meteorological surface data from ERA40 is available on gaussian resolution $\mathrm{N} 80\left(\sim 1.125^{\circ} \times 1.125^{\circ}\right)$ for the period September 1957 to August 2002 with a time step of $6 \mathrm{~h}$. The period 1960 to 2000 is considered. Unfortunately, no daily maximum wind speed (similar to GCM wimax) is available. Therefore, the largest daily value of the four 6 hourly wind speed values of a day is taken for model calibration. See Sects. 3 and 4 for further discussion of this subject.

\subsection{Insurance data and population density}

Our loss model is calibrated based on data provided by the German Insurance Association ("Gesamtverband der Deutschen Versicherer", GDV), which provided yearly sums of loss ratio in Germany for the period 1970 to 1997. They include storm loss related to private buildings and are collected from the member organisations of GDV. The relationship between insured claims and totally insured values is referred to as loss ratio. The time series is nearly inflationadjusted, although the German reunification of 1990 may contribute to slight changes in the loss sums in the early 1990s (Klawa and Ulbrich, 2003). Large losses are usually caused by intense storm events which affect large areas. Summer wind storm events play a negligible role in the annual loss sums used (Klawa and Ulbrich, 2003), and other local events (torrential rain, landslides) are not considered in this investigation. Hence, the time series of annual loss ratio is mainly characterised by the occurrence or absence of such severe storm events within each individual year. Consequently, the loss ratios in 1972 ("Niedersachsen-Orkan", 3 November 1972), 1976 (Gale "Capella“, 3 January 1976) and in 1990 (with five storms in January and February, including "Daria", 26 January 1990) stand out with very high values (cf. Sect. 4). No significant temporal trend of storm damage is revealed in the time series.

The population density distribution is used to estimate the distribution of insured values within a single region/country (see next section). Information about worldwide population numbers are provided by the United Nations Environment Program (UNEP/GRID, 2006) resolved on scale of $1^{\circ} \times 1^{\circ}$ grid boxes.

\section{Methods}

\subsection{Storm loss model}

The statistical model used to estimate monetary storm loss to buildings is based on the daily maximum wind speed. A complete description can be found in Klawa and Ulbrich (2003), but a short description of its main features is given below. The construction of the storm loss model is based on four main assumptions about the occurrence of storm damage:

1. Storm damages are produced when a certain, locally adapted threshold of wind speed is exceeded. This assumption accounts for the adaptation of buildings to the local conditions. This threshold is approximately equal to the local 98 th percentile $\left(v_{98}\right)$ of the daily maximum wind speed.

2. Loss extent of storms increases with the cube of the maximum daily wind speed above the threshold. This exponent is in line with physical argument (the cube of wind speed is proportional to the advection of kinetic energy) and empirical evidence (MunichRe, 2001).

3. Storm damages depend on the local wind climate, and a certain excess of the maximum wind over the percentile value will have less effect where high wind speeds are common. Thus, the daily maximum wind speed excess is scaled by the local 98 th percentile $\left(v_{98}\right)$ value.

4. Insured loss depends on the spatial distribution of insured property values. As this information is not available, we assume that insured property values are proportional to population density (pop).

Based on these assumptions, a so-called daily loss index is computed:

$$
\operatorname{loss}(\text { area }) \propto \underbrace{\text { pop }(\text { area }) \cdot\left(\frac{v(\text { area })}{v_{98}(\text { area })}-1\right)^{3}}_{=\text {loss index }}
$$

As a consequence, wind speeds which are scaled with the local 98th percentile provide a measure of the storm intensity 


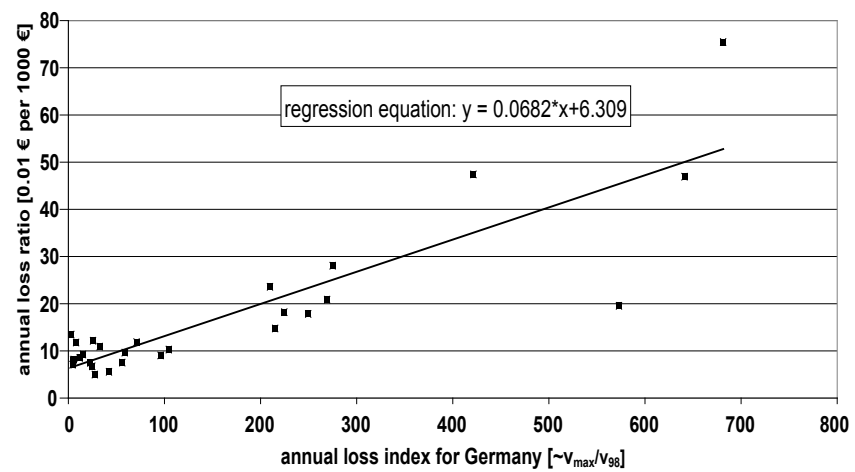

Fig. 1. Linear regression between yearly and regionally accumulated loss indices (ERA40) and annual loss ratio in Germany (GDV) for the period 1970-1997.

which is largely independent of local conditions in a particular area. Note that the use of the cube of the excess over the threshold $v_{98}$ also implies that an absolute increase of wind speeds above that threshold will have a strong (and highly non-linear) effect in loss.

\subsection{Model adjustment}

The loss index (which can be considered a "raw" damage) must be calibrated with loss data from historical storms. As reliable loss data from individual events are not available, the available yearly dataset is used. The daily raw damage (derived from the ERA40 wind data) for each grid point was accumulated both in time (over one year) and space (over all grid points in Germany), resulting in an annual loss time series. The linear regression of observed annual loss ratio of storm damage to buildings in Germany and the accumulated loss index are given in Fig. 1. The obtained regression coefficient $\mathrm{A}\left(6.82 \times 10^{-2}\right)$ is assumed to be approximately the factor of proportionality in Eq. (1), and the constant B (6.309) is the axis intercept. For the estimation of annual storm loss values for Germany, the complete model can be summarised by the following equation:

$\operatorname{loss} \approx A \cdot \sum_{\text {area }}^{\text {Ger }}$ pop(area) $\cdot(\sum_{\text {day }}^{\text {year }} \underbrace{\left(\frac{v(\text { area, day })}{v_{98}(\text { area })}-1\right)^{3}}_{\text {for } v>v_{98} \text { else } 0})+B$

Loss potentials are given in terms of the loss ratio, defined as the ratio between insured claims and totally insured values, and typically have an order of magnitude of $10^{-5}(0.01$ EUR damage per 1000 EUR insured). These relative amounts are more relevant to the insurance companies than absolute values as they are not affected by inflation rates and hence allow long-term comparisons. Here, we compare the obtained yearly sums of storm loss in Germany with the insurance data of the GDV in the period 1970-1997 (Fig. 2). A high corre-

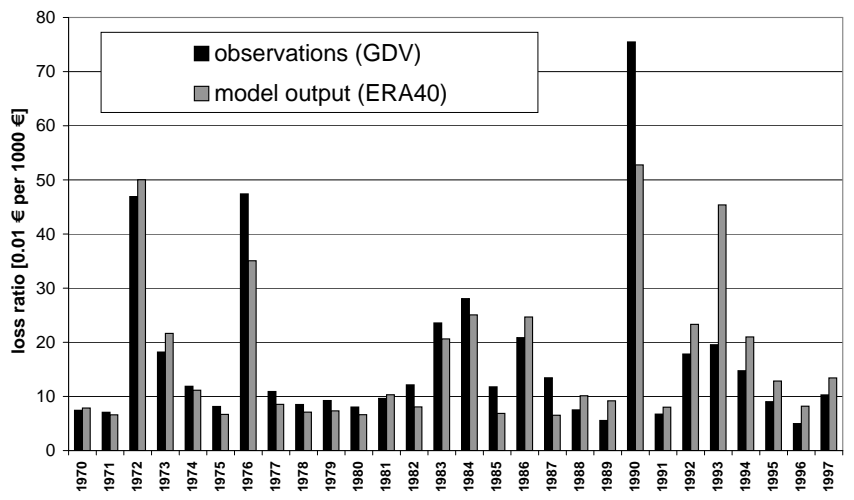

Fig. 2. Annual accumulated loss ratio in Germany for the time period of 1970-1997. Comparison between historical loss data (GDV) and ERA40 derived estimations.

lation between both (correlation coefficient: $r=0.87$ ) is identified, corresponding to an explained variance of $76 \%$.

The storm loss model as described in Eq. (2) can now be applied to GCM data. As the model was calibrated with w6h data, we first considered the same variable for the GCM. Secondly, we applied it to wimax data. As the results of the loss calculations based on both GCM wind variables showed negligible differences (see next section), we decided to concentrate on wimax because it includes the actual information on the gust wind speeds (unlike w6h). The model validation is presented in the next section.

Estimations of storm damage for other European regions are performed the following way: First, the local wind climatologies and population densities are used (following steps 1-4 described above). Second, the model calibration obtained for Germany (i.e. adjusted to the German loss values) is used (cf. Fig. 1). This occurs due to the lack of loss data for the analysed countries. In precise terms, this means that only the transfer function between normed wind to loss is derived from German data, all other information are those which should be applied for this region. Even though this simplification produces loss assessments which may differ from real loss values (e.g., because of different building standards), the climate signals can be expected to give at least a rough estimate of the expected changes. The changes of loss potentials for these regions will be regarded in section six.

\section{Extreme winds and storm loss for the present climate}

In this section, results based on simulated winds of the present climate (20C) are validated against those obtained with ERA40 data. As pointed out in the introduction, the 98th percentile of local wind is particularly important to evaluate changes in the storm climate, as it corresponds to the threshold beyond which losses may be expected. Therefore, we first compare the 98th percentile fields of ERA40 to the ensemble averages of $20 \mathrm{C}$ for the period 1960-2000 in terms 
Table 1. Validation of loss ratios for Germany based on observations (GDV) (1970-1997), ERA40-data (1960-2000) and ECHAM5/MPIOM1 GCM data for present climate conditions (1960-2000). ea means ensemble average (runs 1-3). Units in $0.01 €$ per $1000 €$.

\begin{tabular}{|l|c|c|c|c|c|c|}
\hline & Observations (GDV) & ERA40 & \multicolumn{4}{|c|}{ ECHAM5 } \\
\hline run & & & $\mathbf{1}$ & $\mathbf{2}$ & $\mathbf{3}$ & ea \\
\hline mean & 16.97 & 16.98 & 18.87 & 18.70 & 17.99 & 18.52 \\
\hline standard deviation & 15.72 & 13.27 & 13.12 & 14.26 & 13.79 & 13.73 \\
\hline
\end{tabular}

of the w6h wind (Figs. 3a, b). The spatial distributions are mainly influenced by land-sea-contrasts with largest values over the North Atlantic storm track region. The differences between both datasets are small, with the GCM overestimating the values over the North Atlantic storm track and underestimating them over the Eurasian continental areas (range is between $+/-4 \mathrm{~m} / \mathrm{s}$ ), particularly over high orography. Furthermore, large deviations are perceptible along the European coast lines which result primarely from different spatial resolutions between ERA40 and the GCM. The 98th percentile distribution for the three $20 \mathrm{C}$ ensemble runs show a very high spatial coherence, e.g. differences over Germany are smaller than $2 \%$ (data not shown).

As expected, wimax is larger than w6h for the whole study area (cf. Figs. 3b, c). Differences between the 98th percentiles of the two GCM wind variables are largest over the main North Atlantic storm track region, while they are almost negligible over continental areas e.g. Central Europe. As the normalised wind distributions (with 98th percentile) for individual grid points also show similar statistical characteristics for both variables (data not shown), it is acceptable to use the model calibrated with w6h data with wimax data.

Next, we consider the annual loss estimations over Germany. The mean loss ratio of the GCM simulations is on average circa $10 \%$ larger than both the observational and ERA40 derived loss data (Table 1). This discrepancy cannot be solely attributed to the use of wimax, as the $20 \mathrm{C}$ mean loss value with w6h is also larger than ERA40 and GDV values (ensemble average: $18.10 \times 10^{-5} €$ ). In terms of standard deviation, values for both wimax and w6h (ensemble average: $13.07 \times 10^{-5} €$ ) are close to the ERA40 values, and slightly lower than the GDV data (cf. Table 1). The time series of annual loss ratio derived for the first ensemble member is shown in Fig. 4. Please note that this figure has a different vertical scale than Fig. 1. Its main features are comparable to the other two runs and no temporal trends are detected. In summary, the application of the storm loss model to the GCM data correspondent to recent climate conditions provides realistic results in comparison to observational near data and historical loss data.
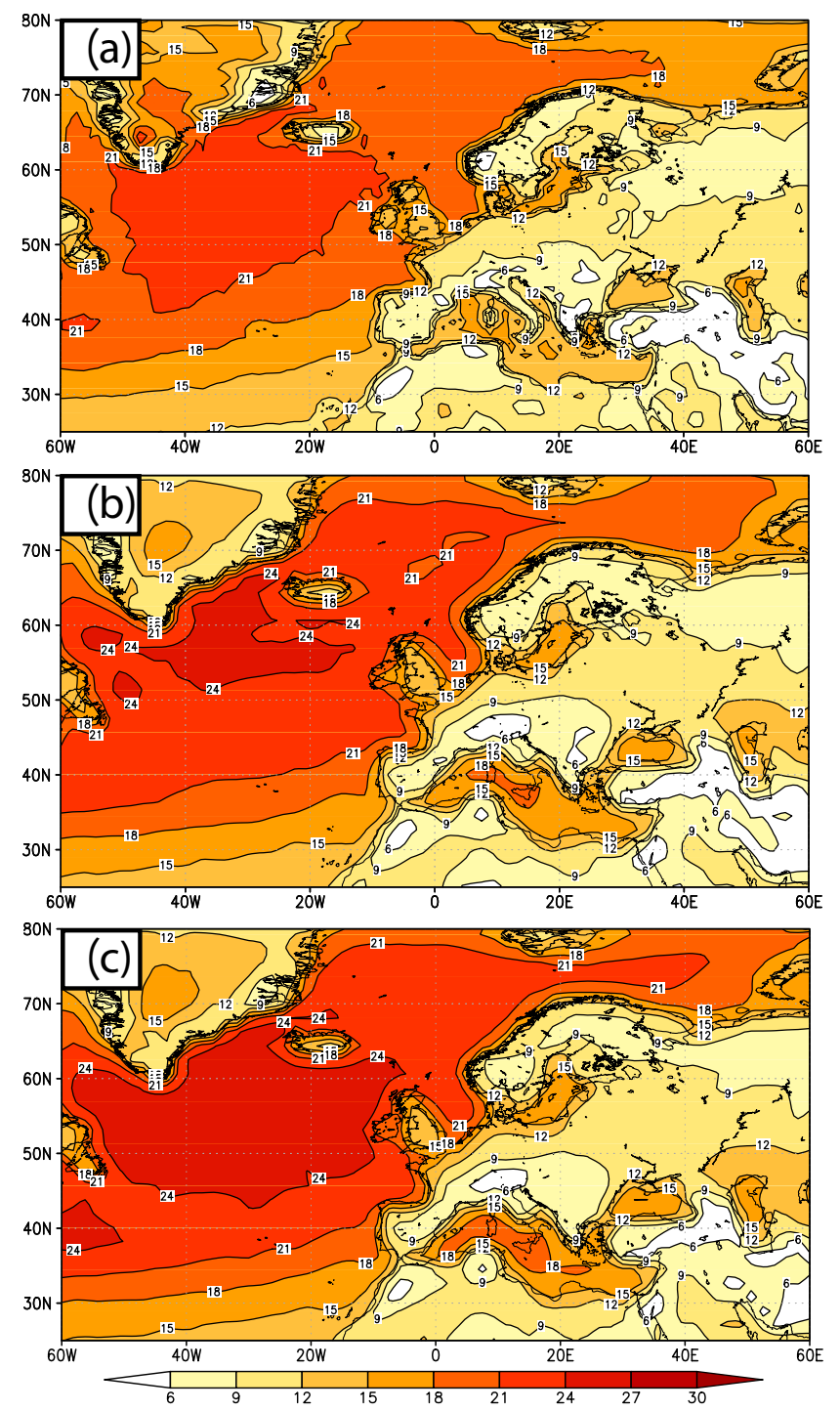

Fig. 3. 98th percentile of $10 \mathrm{~m}$ wind speed for (a) ERA40 data (interval: 3 [m/s]) (b) ECHAM5/MPI-OM1 GCM data for the present climate (1960-2000), w6h, ensemble average (c) same as (b) but for wimax. Panel (c) adapted from Pinto et al. (2007).

\section{Changing storms in a future climate}

In this section, GCM results derived from future climate conditions (end of the 21 st century) are analysed and compared 


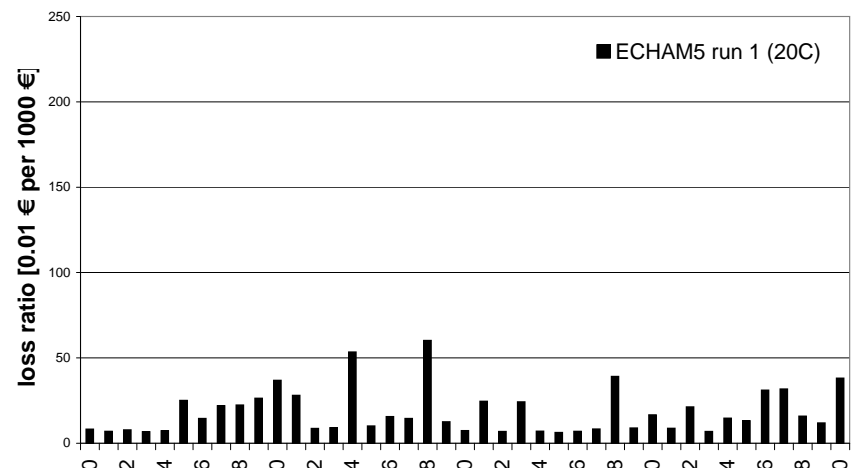

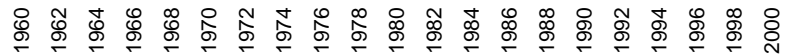

Fig. 4. Time series of annual loss ratios for Germany, first ensemble simulation from ECHAM5/MPI-OM1 GCM with present climate conditions (1960-2000).

to the results from the previous section. Before analysing the changes in storm loss potentials for Germany, we consider the changes in storm activity and of the extreme winds over the North Atlantic region and Europe. In terms of the storm system activity, the changes in cyclone track density and intensity of cyclones are of particular interest. Such results were derived by Pinto et al. (2007) for the simulations considered in this paper with the cyclone track algorithm described in Pinto et al. (2005). Further technical details can be found in those references. Here, we concentrate on the changes of frequency and intensity of the 5\% strongest cyclones (hereafter "extreme cyclones") following the definition given in Leckebusch et al. (2006). Such extreme cyclones typically feature strong pressure gradients on their flanks, which in turn produce the large wind gusts. Therefore, it is reasonable to assume that changes in the number and intensity of such extreme cyclones are responsible for changes in the higher wind percentiles. The connection between deeper cyclones and higher extreme wind speeds in GCMs has been previously documented e.g. by Knippertz et al. (2000) and Leckebusch et al. (2006).

Figure 5 includes the climate signal of cyclone characteristics and 98th wind percentile for members of the A1B ensemble (upper four panels). Changes of cyclone track density and cyclone intensity of extreme cyclones for the first run (Fig. 5a) show an increase in the number of intense cyclones between Scotland and Scandinavia, which goes very well with the significantly enhanced values of the 98th wind percentile over Western and Central Europe (Students t-Test 95\% confidence level) for the same run (Fig. 5b), particularly over the North and Baltic Sea and the adjacent areas. The second run shows a similar pattern of change with lower loadings (wind percentiles shown in Fig. 5c), while the third run shows little significant results (Fig. 5d). In spite of these differences, it appears that the signal structure is similar. The impression of similarity is further supported by the results obtained from the A2 experiments (Fig. 5, lower four panels).
Typically, loadings are higher than in A1B experiments. The zonally elongated area of increased extreme winds reaching from Europe into the Asian continent is found in all ensemble members. Hence, Western Europe is expected be more exposed to the influence of extreme wind storms than under the present climate conditions. This result is attributed to the changes detected for extreme cyclones near the British Isles (Figs. 5a, e).

Considering now other regions, the most striking feature is a widespread decrease of the extreme wind speeds at lower latitudes (e.g. Mediterranean) and at polar latitudes (e.g., between Greenland, North Scandinavia and Spitsbergen Isles). This feature is detected in all simulations (with changing magnitudes), showing a very coherent spatial pattern. The changes in the polar regions are also related to alterations in the surface roughness which in turn evolves from the retreat of sea ice.

\section{Changing loss in a future climate}

Based on these wind speed signals, increased losses over Western and Central Europe and decreased losses for northern Scandinavia and the Mediterranean may be intuitively expected. This train of thought implicitly assumes that buildings will have the same characteristic weak points with respect to wind as today, and no adaptation takes place to a changed wind climate. The alternative, a rapid and complete adaptation to a changing wind climate, must also be taken into account. Both possibilities are considered using the loss model: Without adaptation, the 98th wind percentiles remain those of the present day climate, while with adaptation those of the 21 st century are used. The results for ensemble averages consider the three individual runs as one single extended simulation with 120 years of data. Changes in loss potentials for Germany considering both individual runs and ensemble means are presented in Table 2, giving percentage changes of the mean and standard deviation of the loss time series. Significant differences (Students t-Test 95\% confidence level) between the present and future loss data are denoted by shaded boxes. If adaptation is assumed, there is no significant change in terms of mean values, though deviations are positive in most cases (ranging from $-6 \%$ to $+45 \%$ ). In ensemble average, the changes are $+6.3 \%$ for $\mathrm{A} 1 \mathrm{~B}$ and $+13.3 \%$ for A2. If no adaptation is considered, changes are positive for all simulations, and the changes are significant in ensemble average, reaching $+40.2 \%$ for A1B and $+49.1 \%$ for A2. More important, the changes of the standard deviation are larger and significant in 5 from 6 cases with full adaptation, even exceeding $100 \%$ for the first A2 simulation. The changes in ensemble mean reach circa $+50 \%$ and $+74 \%$ for the A1B and A2 experiments. As expected, if no adaptation to future storm conditions is considered, the changes of the standard deviation of annual loss potentials are even more pronounced (over $100 \%$ for the ensemble averages). 

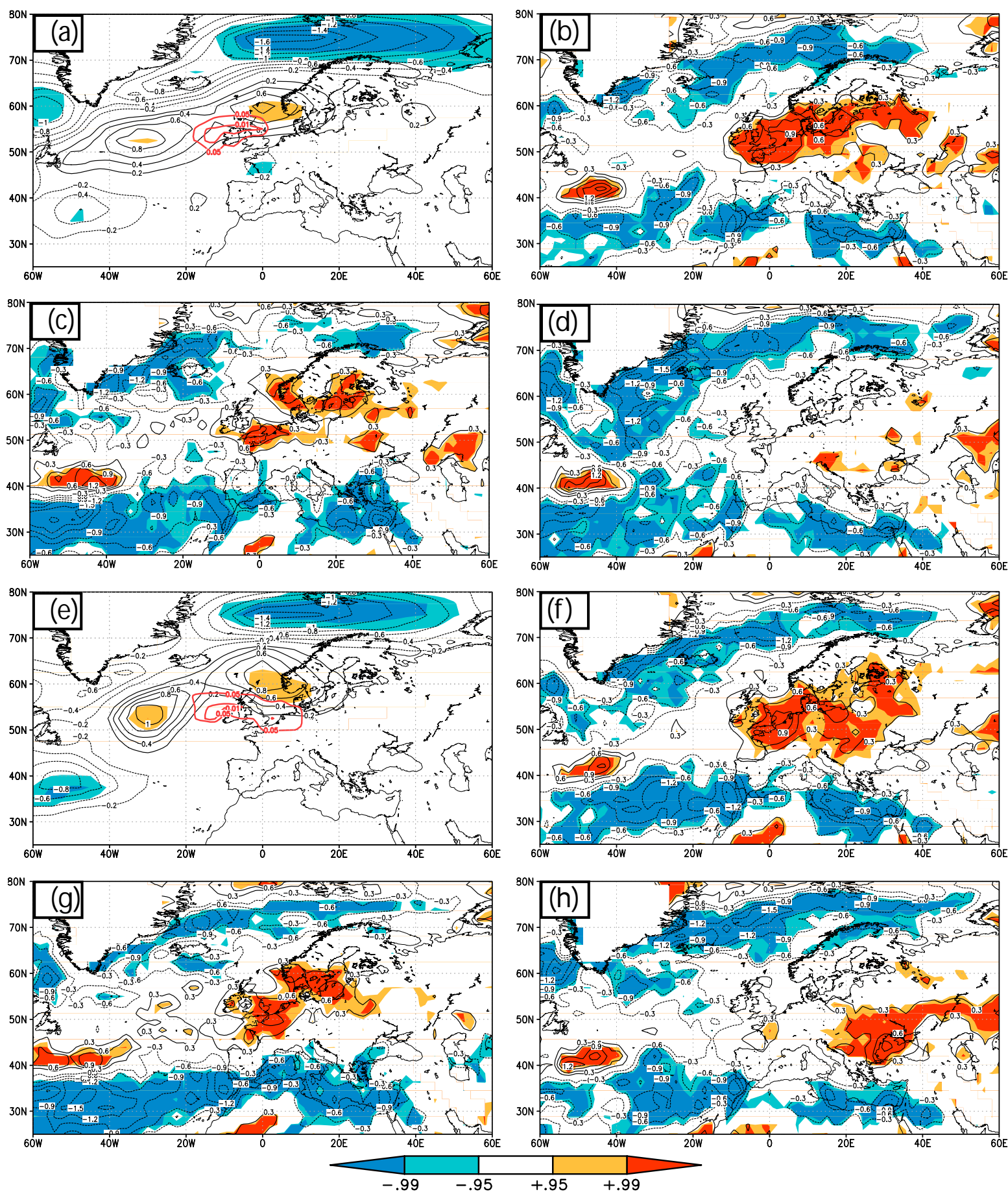

Fig. 5. Climate signals for characteristics of extreme cyclones and 98th percentile of $10 \mathrm{~m}$ wind speed (wimax) between present (1960-2000) and future (2060-2100) climate conditions based on the ECHAM5/MPI-OM1 simulations. (a) cyclone track density A1B first run minus 20C first run (interval: 0.2 [cyclone days/winter]). Red isolines limit areas where a significant change of cyclone intensities is detected (0.05: 95\%-confidence levels; 0.01 same for 99\%-confidence level). (b) 98th percentile for wimax wind speed (interval: 0.3 [m/s]), A1B first run minus 20C first run (c) same as (b) but for A1B second run (d) same as (b) but for A1B third run (e) same as (a) but for A2 first run. (f) same as (b) but for A2 first run. (g) same as (f) but for A2 second run. (h) same as (f) but for A2 third run. On all panels, areas with significance differences (95\%- and 99\%- confidence levels) are in colour (t-test on winter basis). 
Table 2. Climate Change Signal of loss ratio for Germany (\%). Differences between present (1960-2000) and future (2060-2100) climate conditions based on the ECHAM5/MPI-OM1 simulations. ea means ensemble average (runs 1-3). Significant differences (95\%- confidence level) are shaded gray (t-test on annual basis).

\begin{tabular}{|c|c|c|c|c|c|c|c|c|}
\hline \multirow{3}{*}{$\begin{array}{l}\text { scenario } \\
\text { run }\end{array}$} & \multicolumn{8}{|c|}{ ECHAM5 } \\
\hline & \multicolumn{4}{|c|}{ A1B } & \multicolumn{4}{|c|}{ A2 } \\
\hline & 1 & 2 & 3 & ea & 1 & 2 & 3 & ea \\
\hline $\begin{array}{l}\text { mean } \\
\text { with adaption }\end{array}$ & $+6.9 \%$ & $+12.1 \%$ & $-0.7 \%$ & $+6.3 \%$ & $+42.9 \%$ & $-3.7 \%$ & $+1.8 \%$ & $+13.3 \%$ \\
\hline $\begin{array}{c}\text { mean } \\
\text { no adaption }\end{array}$ & $+60.4 \%$ & $+50.7 \%$ & $+8.2 \%$ & $+40.2 \%$ & $+110 \%$ & $+27.0 \%$ & $+11.7 \%$ & $+49.1 \%$ \\
\hline $\begin{array}{c}\text { standard deviation } \\
\text { with adaption }\end{array}$ & $+85.5 \%$ & $+35.0 \%$ & $+24.7 \%$ & $+49.5 \%$ & $+127 \%$ & $+43.8 \%$ & $+39.3 \%$ & $+73.9 \%$ \\
\hline $\begin{array}{c}\text { standard deviation } \\
\text { no adaption }\end{array}$ & $+189 \%$ & $+84.6 \%$ & $+34.4 \%$ & $+112 \%$ & $+221 \%$ & $+96.4 \%$ & $+54.9 \%$ & $+137 \%$ \\
\hline
\end{tabular}

In order to further explore these changes, we analyse individual time series of annual loss ratios for Germany. As an example, time series of some of A1B and A2 runs are shown in Fig. 6. Compared with the time series for the $20 \mathrm{C}$ (cf. Fig. 4), the stronger year to year variability is immediately apparent: e.g., the time series of the first A1B run (Fig. 6a) features an exceptional year (2079). The amount of damage is about three times the maximum annual loss ratio in the control period when adaptation is taken into account, and five times as high without. Note that large loss ratio values in individual years can also be found in the other runs (e.g. the A2 runs in Figs. 6b, c), though they typically feature smaller magnitudes. These exceptionally high loss ratios could arise both from the occurrence of single extraordinary storm events (unknown under the present climate conditions) or from a multiplicity of strong winter storms similar to those detected in the present climate. We looked at the daily "raw" damage data e.g. during the year 2079 for the first A1B run and compared its characteristics to other years and other GCM-derived time series, particularly those from the $20 \mathrm{C}$ runs. We found that such exceptional years feature an increased number of intense storms, noticeable as single peaks in the daily time series. However, these storms do not differ drastically in terms of their typical characteristics from other storm events (irrespective of the large magnitudes). Therefore, it can be assumed that increases in loss potentials may be primarily associated with an increased number of intense storms (agreeing with the results for intense cyclones, cf. section five) and not necessarily with the occurrence of single extraordinary events with intensity unknown in the present climate. However, this conclusion must be regarded as preliminary, and more detailed studies are necessary. These aspects, particularly in terms of changes in the magnitude of storms (both in terms of intensity and affected areas) and consequently on their associated return periods will be addressed in future investigations.

In order to estimate climate signals of loss potentials for the other European regions, we apply the storm loss model to the United Kingdom, France, Portugal/Spain and Nor-
way/Sweden, nonetheless making use of the calibration for Germany. This approximation is acceptable as all five regions feature a similar economical development, and hence similar insured values (per capita) may be expected (see also considerations in section three). The climate change signals for the mean and standard deviation are presented in Table 3 in terms of ensemble averages for A1B and A2. The first impression is that the results are comparable to those for Germany: There is typically a small increase in mean values (though often not significant), while changes in standard deviation are significant in almost all cases. In fact, the results for France and the United Kingdom are very similar to those for Germany. Nevertheless, note that for the A2 experiment a minor (not significant) decrease in loss potentials is obtained for the United Kingdom if full adaptation in considered. If the corresponding single runs are considering, the changes are always smaller than minus $10 \%$.

For Portugal/Spain and Norway/Sweden, no significant changes for average loss are detected, and changes range only up to $+/-10 \%$. Please note that the calculations for Portugal/Spain have the particularity that the 98 th percentiles in the scenario periods are actually lower than the ones for 20C. Considering full adaptation, this would mean that at the end of the 21 st century the basic structure of buildings would be worse than today. This assumption may be regarded as realistic, as by longer absence of intense storms the incentive to maintain (or enhance) the structure of the buildings (and hence their resistance to storms) is reduced. Changes in standard deviation are significant for A1B alone. For Norway/Sweden, a significant increase in standard deviation is identified for both scenarios with and without adaptation.

\section{Summary and conclusions}

We have analysed an ensemble of climate experiments with the ECHAM5/OM1 GCM in order to infer changes in storm induced loss potentials over Europe. This investigation is done primarily for Germany, and then extended to other 
Table 3. Climate Change Signal of loss ratio for different European regions (\%). Differences between present (1960-2000) and future (20602100) climate conditions based on the ECHAM5/MPI-OM1 simulations. ea means ensemble average (runs 1-3). Significant differences (95\%-confidence level) are shaded gray (t-test on annual basis).

\begin{tabular}{|l|c|c|c|c|c|c|c|c|c|c|}
\hline & \multicolumn{9}{|c|}{ ECHAM5 (ensemble averages) } \\
\hline region & \multicolumn{2}{|c|}{ Germany } & \multicolumn{2}{|c|}{ U.K. } & \multicolumn{2}{c|}{ France } & \multicolumn{3}{c|}{$\begin{array}{c}\text { Portugal } / \\
\text { Spain }\end{array}$} & \multicolumn{2}{c|}{$\begin{array}{c}\text { Norway I } \\
\text { Sweden }\end{array}$} \\
\hline scenario & $\mathrm{A} 1 \mathrm{~B}$ & $\mathrm{~A} 2$ & $\mathrm{~A} 1 \mathrm{~B}$ & $\mathrm{~A} 2$ & $\mathrm{~A} 1 \mathrm{~B}$ & $\mathrm{~A} 2$ & $\mathrm{~A} 1 \mathrm{~B}$ & $\mathrm{~A} 2$ & $\mathrm{~A} 1 \mathrm{~B}$ & $\mathrm{~A} 2$ \\
\hline $\begin{array}{c}\text { mean } \\
\text { with adaption }\end{array}$ & $+6 \%$ & $+13 \%$ & $+8 \%$ & $-4 \%$ & $+3 \%$ & $+34 \%$ & $+8 \%$ & $+10 \%$ & $+1 \%$ & $+4 \%$ \\
\hline $\begin{array}{c}\text { mean } \\
\text { no adaption }\end{array}$ & $+40 \%$ & $+49 \%$ & $+43 \%$ & $+24 \%$ & $+11 \%$ & $+44 \%$ & $-5 \%$ & $-5 \%$ & $+7 \%$ & $+10 \%$ \\
\hline $\begin{array}{c}\text { standard deviation } \\
\text { with adaption }\end{array}$ & $+50 \%$ & $+74 \%$ & $+37 \%$ & $+19 \%$ & $+25 \%$ & $+132 \%$ & $+74 \%$ & $+36 \%$ & $+29 \%$ & $+66 \%$ \\
\hline $\begin{array}{c}\text { standard deviation } \\
\text { no adaption }\end{array}$ & $+112 \%$ & $+137 \%$ & $+119 \%$ & $+85 \%$ & $+37 \%$ & $+156 \%$ & $+63 \%$ & $+11 \%$ & $+58 \%$ & $+89 \%$ \\
\hline
\end{tabular}

countries of Western Europe. We used a simple storm loss model based on the following assumptions (a): Losses increase with the cube of the maximum daily wind speed (b): Losses only occur if a high climatological wind percentile (98th) is exceeded (c): Losses are proportional to the difference between the occurred daily maximum wind value and the 98th percentile (d): Insured loss depends on the spatial distribution of insured property values.

Based on the results for five regions, it can be concluded that a higher year-to-year variability of loss potentials may be expected in a future climate over Western and Central Europe. Without adaptation, average loss tolls increase significantly for France, the United Kingdom and Germany. In most cases, the increases are not statistically significant with adaptation. Also, there is a high spread between the changes in storm loss as estimated from the individual runs for the same experiment. Considering the changes in cyclone counts and intensity as well as those in daily maximum wind speeds, the different runs show many common features (Fig. 5) e.g. an enhancement of extreme cyclone intensities over Western Europe (cf. also Pinto et al., 2007), which in turn induces an increase of the 98th wind percentiles in a zonally elongated area across Europe. The relationship between wind percentiles and storm loss numbers is, however, highly nonlinear (cf. Klawa and Ulbrich, 2003), so significant changes in extreme wind speeds do not necessarily imply similar results for the accumulated storm losses.

One of the most pertinent results of our study is the increase in interannual variability of insured losses in a modified climate, which in turn indicates a diminution in the return period of extreme rare events. This effect seems to be associated with an increased probability for years with multiple events and hence of large loss numbers, which may severely affect management strategies of the insurance companies. This result is valid for all five regions and is particularly large for Germany, the United Kingdom and France. The larger signals obtained for no-adaptation calculations further indicate the need of a change in political/management terms in relation of risk strategies and changes in infrastructure char- acteristics to account for the changing local wind characteristics induced by climate change.

The storm loss model has recently been applied to single runs with the ECHAM4/OPYC3, HadAM3P and HadCM3 models by Leckebusch et al. (2007). The results indicate an increase in loss potentials for Germany and the United Kingdom with the ECHAM4 and HadCM3 GMs, while the HadAM3P has less pronounced changes and even negative changes over Germany. The main difference to the ECHAM5 results is that the changes in terms of standard deviation are typically lower for those three GCMs (except for HadCM3 for the United Kingdom). Causes for the differences are not clear yet, but a strong coherence between the changes in loss potentials and the frequency of extreme cyclones was identified for the individual GCMs (cf. Leckebusch et al., 2006): e.g. the HadAM3P show more moderate changes in terms of extreme cyclones than ECHAM5. Hence, the different climate signals in terms of cyclone activity detected in the individual GCMs are surely one of the factors corroborating to the dissimilar signals in storm losses obtained for the four GCMs.

With respect to the insecurities of our approach, we note that our loss model implicitly assumes that there is no change in socio-economic factors (e.g. changes in demography and hence density of insured values) over a period of 100 years. However, such factors will surely undergo changes in the future. Missing perspectives of these factors may constitute a source of uncertainty which is as large as the meteorological aspects investigated in the current paper. Further studies are necessary in order to assess changes of loss potentials derived from Regional Circulation Models, which feature a higher resolution than GCMs.This is ongoing research e.g. in the ENSEMBLES project. Last but not least, the environmental politics of the industrialized countries will be primarily responsible whether we are heading for a restricted climate change (e.g. B1, A1B scenarios) or for a strong change (e.g. A2, A1F scenarios) in the earth's climate whose consequences can hardly be foreseen at present. 

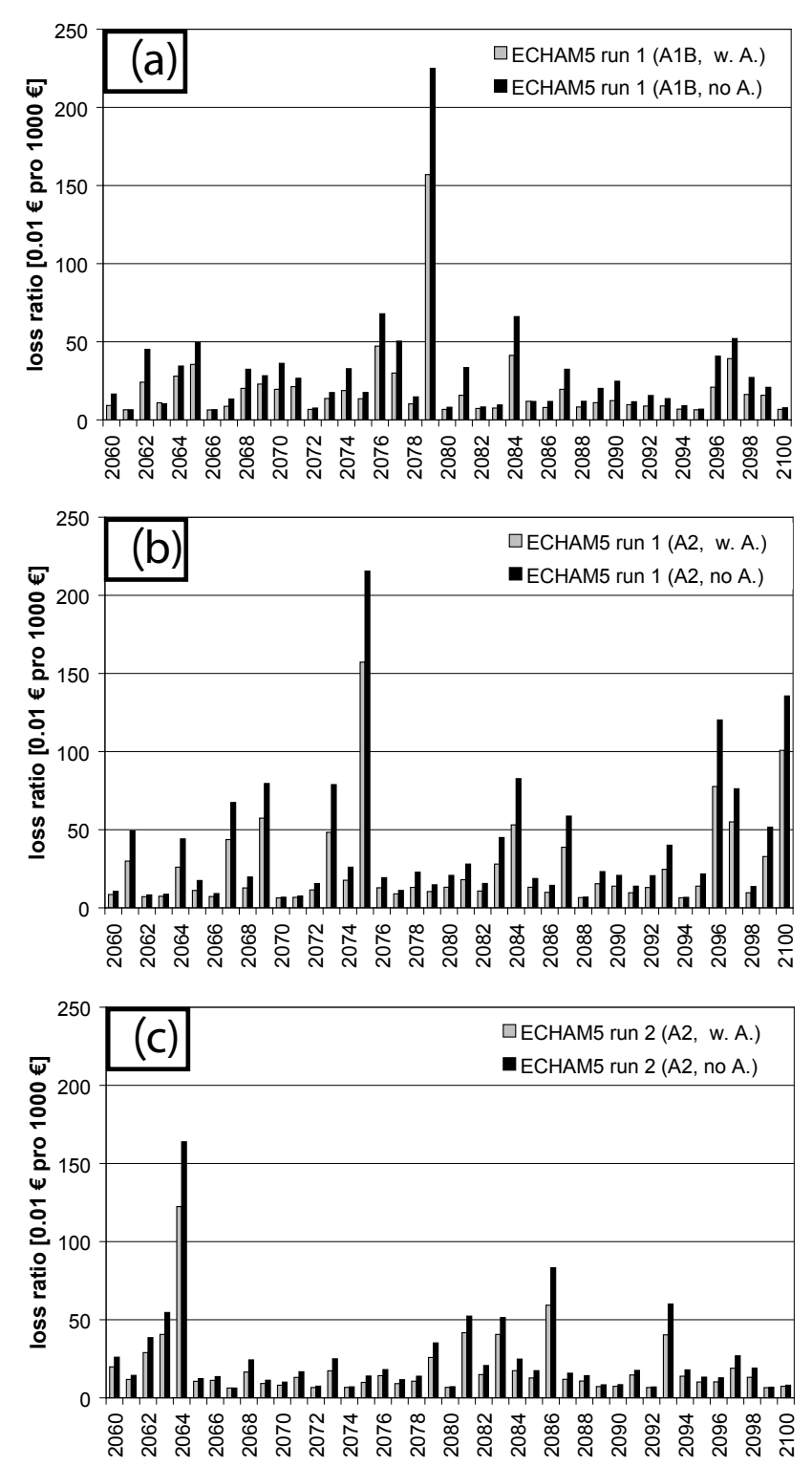

Fig. 6. Time series of annual loss ratios for Germany based on ECHAM5/MPI-OM1 GCM data for future climate conditions (1960-2000). (a) A1B scenarios, first ensemble member. Grey columns for values with adaptation, black columns for values with no-adaption. (b) as a) but for A2 scenario, first ensemble member (c) as (a) but for A2 scenario, second ensemble member.

Acknowledgements. This work was supported by the European Union Programme Energy, Environment and Sustainable Development under contracts EVK2-CT-2001-00118 (MICE) and GOCE-CT-2003-505593-ENSEMBLES. We acknowledge the provision of annual loss data by the German Insurance Association GDV. We would like to kindly thank Erich Roeckner and the MPI for Meteorology (Hamburg, Germany) by order of the Federal Environment Agency for support and providing the ECHAM5 data and the DKRZ/WDCC (Hamburg, Germany) for computer capacity. J. G. Pinto and E. L. Fröhlich contributed equally to this work. The authors would like to thank S. Zacharias, M. Karremann and S. Ulbrich for preparing some of the figures.

Edited by: A. Mugnai

Reviewed by: I. Kan and two other referees

\section{References}

Bärring, L. and von Storch, H.: Scandinavian storminess since about 1800, Geophys. Res. Lett., 31, L20 202, doi:10.1029/2004GL020441, 2004.

Bengtsson, L., Hodges, K. I., and Roeckner, E.: Storm Tracks and Climate Change, J. Climate, 19, 3518-3543, 2006.

Berz, G.: Naturkatastrophen im 21. Jahrhundert - Trends und Schadenpotentiale, DKKV, Extreme Naturereignisse, BonnLeipzig, pp. 253-264, 2001.

Carnell, R. E., Senior, C. A., and Mitchell, J. F. B.: An assessment of measures of storminess: simulated changes in northern hemisphere winter due to increasing $\mathrm{CO}_{2}$, Clim. Dyn., 12, 467-476, 1996.

Emanuel, K.: Increasing destructiveness of tropical cyclones over the past 30 years, Nature, 436, 686-688, doi:10.1038/nature03906, 2005.

Geng, Q. and Sugi, M.: Variability of the North Atlantic Cyclone Activity in Winter Analyzed from NCEP-NCAR Reanalysis data, J. Climate, 14, 3863-3873, 2001.

Geng, Q. and Sugi, M.: Possible change of extratropical cyclone activity due to enhanced greenhouse gases and sulfate aerosols study with a high-resolution AGCM, J. Climate, 16, 2262-2274, 2003.

IPCC: Climate Change 1995: The science of climate change, edited by: Houghton J. T., Meira Filho, L. G., Callander, B. A., et al., Intergovernmental Panel on Climate Change, Cambridge University press, 1996.

IPCC: Climate Change. The scientific Basis, edited by: Houghton, J. T., Ding, Y., Griggs, D. J., et al., Intergovernmental Panel on Climate Change, Cambridge University press, 2001.

Klawa, M. and Ulbrich, U.: A model for the estimation of storm losses and the identification of severe winter storms in Germany, Nat. Hazard Earth Syst. Sci., 3, 725-732, 2003.

Knippertz, P., Ulbrich, U., and Speth, P.: Cyclone activity and wind speeds in a transient GHG experiment, Clim. Res., 15, 109-122, 2000.

Lambert, S. J.: The Effect of Enhanced Greenhouse Warming on Winter Cyclone Frequencies and Strengths, J. Climate, 8, 14471452, 1995.

Lambert, S. J.: Intense extratropical northern hemisphere winter cyclone events: 1899-1991, J. Geophys. Res., 101, 21 319-21 325, 1996.

Lambert, S. J. and Fyfe, J. C.: Changes in winter cyclone frequencies and strengths simulated in enhanced greenhouse warming experiments: results from the models participating in the IPCC diagnostic exercise, Clim. Dyn., 26, 713-728, doi:10. 1007/s00382-006-0110-3, 2006.

Lambert, S. J., Sheng, J., and Boyle, J. S.: Winter cyclone frequencies in thirteen models paricipating in the Atmospheric Model Intercomparison Project (AMIP1), Clim. Dyn., 19, 1-16, 2002.

Leckebusch, G. C. and Ulbrich, U.: On the relationship between cyclones and extreme windstorm events over Europe under climate 
change, Global Planet. Change, 44, 181-193, 2004.

Leckebusch, G. C., Koffi, B., Ulbrich, U., Pinto, J. G., Spangehl, T., and Zacharias, S.: Analysis of frequency and intensity of winter storm events in Europe on synoptic and regional scales from a multi-model perspective, Climate Research, Special Issue to the Mice project, 31, 59-74, 2006.

Leckebusch, G. C., Ulbrich, U., Fröhlich, E. L., and Pinto, J. G.: Property loss potentials for European mid-latitude storms in a changing climate, Geophys. Res. Lett., accepted, 2007.

Marsland, S. J., Haak, H., Jungclaus, J. H., Latif, M., and Roske, F.: The Max-Planck-Institute global ocean/sea ice model with orthogonal curvilinear coordinates, Ocean modelling, 5, 91-127, 2003.

MunichRe: Naturkatastrophen in Deutschland - Schadenerfahrungen und Schadenpotentiale, Publication of Munich Reinsurance Company, 1999.

MunichRe: Winter storms in Europe (II) - Analysis of 1999 losses and loss potentials, Publication of Munich Reinsurance Company, 2001.

Nakićenović, N., Alcamo, J., Davis, G., de Vries, B., Fenhann, J., Gaffin, S., Gregory, K., Grübler, A., Jung, T. Y., Kram, T., Rovere, E. L. L., Michaelis, L., Mori, S., Morita, T., Pepper, W., Pitcher, H., Price, L., Raihi, K., Roehl, A., Rogner, H.-H., Sankovski, A., Schlesinger, M., Shukla, P., Smith, S., Swart, R., Rooijen, S. V., Victor, N., and Dadi, Z.: Emission Scenarios. A Special Report of Working Group III of the Intergovernmental Panel on Climate Change, Cambridge University press, Cambridge, UK, 2000.

Paciorek, J. C., Risbey, J. S., Ventura, V., and Rosen, R. D.: Multiple Indices of Northern Hemisphere Cyclonic Activity, Winters 1949-99, J. Climate, 15, 1573-1590, 2002.

Palutikof, J. P. and Skellern, A. R.: Storm Severity over Britain, A Report to Commercial Union General Insurance, Climatic Research Unit, School of Environmental Sciences, University of East Anglia, Norwich (UK), 1991.

Pinto, J. G., Spangehl, T., Ulbrich, U., and Speth, P.: Sensitivities of a cyclone detection and tracking algorithm: individual tracks and climatology, Meteorol. Z., 14, 823-838, 2005.

Pinto, J. G., Spangehl, T., Ulbrich, U., and Speth, P.: Assessment of winter cyclone activity in a transient ECHAM4-OPYC3 GHG experiment, Meteorol. Z., 15, 279-291, 2006.

Pinto, J. G., Ulbrich, U., Leckebusch, G. C., Spangehl, T., Reyers, M., and Zacharias, S.: Changes in barocline wave activity in an ensemble of ECHAM5/MPI-OM1 simulations for three different SRES scenarios, Clim. Dyn., in press, doi:10.1007/s00382-0070230-4, 2007.
Raible, C. C. and Blender, R.: North Hemisphere Midlatitude cyclone variability in GCM-simulations in different ocean representations, Clim. Dyn., 22, 239-248, 2004.

Roeckner, E., Bäuml, G., Bonaventura, L., Brokopf, R., Esch, M., Giorgetta, M., Hagemann, S., Kirchner, I., Kornblueh, L., Manzini, E., Rhodin, A., Schlese, U., Schulzweida, U., and Tompkins, A.: The atmospheric general circulation model ECHAM5. Part I: Model description, MPI Report, Nr. 249, 2003.

Schinke, H.: On the Occurence of Deep Cyclones over Europe and the North Atlantic in the Period 1930-1991, Beitr. Phys. Atmosph., 66, 223-237, 1993.

SwissRe: Storm over Europe - An underestimated risk, Swiss Re publishing, Zürich, 2000.

SwissRe: The effects of climate change: Storm damage in Europe on the rise, Swiss Re publishing, Focus Report, Zürich, Can be downloaded from http://www.swissre.com, 2006.

Ulbrich, U., Fink, A., Klawa, M., and Pinto, J. G.: Three extreme storms over Europe in December 1999, Weather, 56, 70-80, 2001.

Ulbrich, U., Brücher, T., Fink, A., Leckebusch, G., Krüger, A., and Pinto, J. G.: The Central European Floods in August 2002. Part I: Rainfall periods and flood development, Weather, 58, 371-377, 2003a.

Ulbrich, U., Brücher, T., Fink, A., Leckebusch, G., Krüger, A., and Pinto, J. G.: The Central European Floods in August 2002. Part II: Synoptic causes and considerations with respect to climate change, Weather, 58, 434-442, 2003b.

UNEP/GRID: The United Nations Environment Programme/ Global Resource Information Database, http://www.na.unep.net/ datasets/datalist.php, 2006.

Uppala, S., Kallberg, P., Hernandez, A., Saarinen, S., Fiorino, M., Li, X., Onogi, K., Sokka, N., Andrae, U., and Da Costa Bechtold, V.: ERA-40: ECMWF 45-year reanalysis of the global atmosphere and surface conditions 1957-2002, ECMWF Newsletter, 101, 2-21, 2004.

von Storch, H., Guddal, J., Iden, K., Jónsson, T., Perlwitz, J., Reistad, M., de Ronde, J., Schmidt, H., and Zorita, E.: Changing Statistics of storms in the North Atlantic, MPI Report, Nr. 116, p. 18, 1993.

WASA-Group: Changing Waves and Storms in the Northeast Atlantic?, Bulletin of the American Meteorological Society, 79, 741-760, 1998.

Webster, P. J., Holland, G. J., Curry, J. A., and Chang, H.R.: Changes in Tropical Cyclone Number, Duration, and Intensity in a Warming Environment, Science, 309, 1844-1846, doi:10.1126/science.1116448, 2005. 